\title{
ERRATUM
}

\section{WHEN A SMILE DOES NO GOOD: CREATIVITY REDUCTION AMONG AVOIDANCE- VERSUS APPROACH-ORIENTED INDIVIDUALS IN DYADIC INTERACTIONS}

[Int. J. Innovation Management, Vol. 20, No. 4 (2016) 1640007]

\author{
KEN FUJIWARA \\ Faculty of Human Sciences, Osaka University of Economics \\ 2-2-8 Oosumi, Higashi-Yodogawa-ku, Osaka 533-8533, Japan \\ ken.fuji@osaka-ue.ac.jp \\ KOSUKE TAKEMURA \\ Faculty of Economics, Shiga University \\ 1-1-1 Banba, Hikone, Shiga 522-8522, Japan \\ SATOKO SUZUKI \\ Graduate School of Management, Kyoto University \\ Yoshida Honmachi, Sakyo-ku \\ Kyoto 606-8501, Japan
}

Published 3 June 2016 
Figure 1 and figure caption has now been changed as follows:

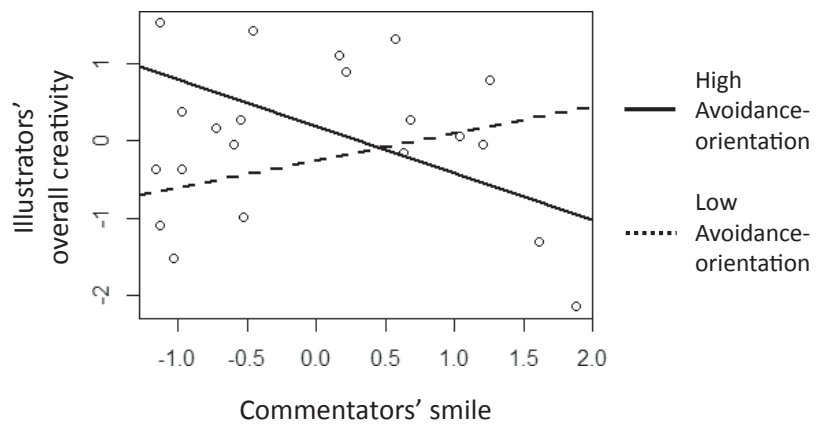

(a)

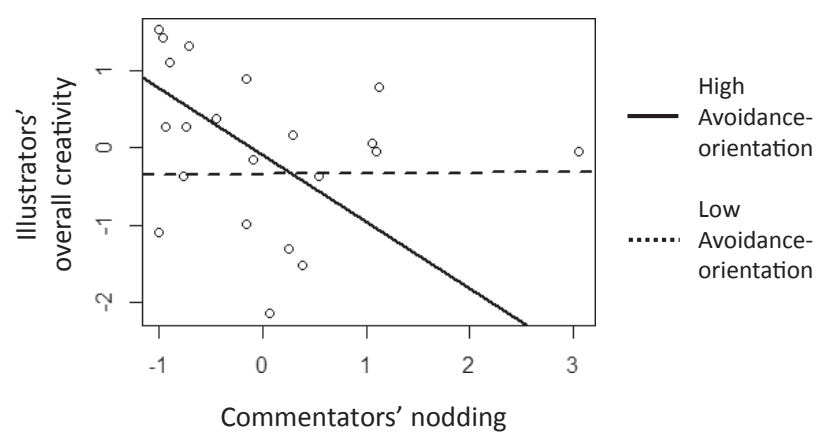

(b)

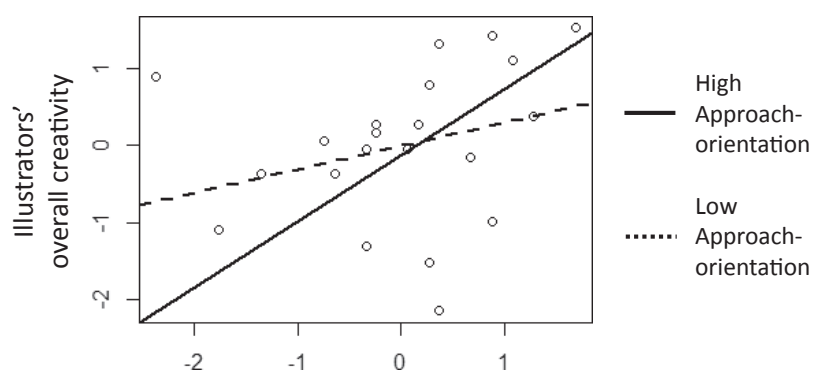

Commentators' verbal approval

(c)

Fig. 1. The interaction effect of the illustrator's avoidance-orientation and the commentator's smile (a) and nodding (b), and the illustrator's approach-orientation and the commentator's verbal approval (c). 